\title{
Spinocerebellar ataxia type 15/16
}

INSERM

\section{Source}

INSERM. (1999). Orphanet: an online rare disease and orphan drug data base.

Spinocerebellar ataxia type 15/16. ORPHA:98769

Spinocerebellar ataxia type 15/16 (SCA15/16) is a rare subtype of type I autosomal dominant cerebellar ataxia (ADCA type I; see this term). It is characterized by cerebellar ataxia, tremor and cog nitive impairment. 